\section{ECCOMAS}

Proceedia
COMPDYN 2021

$8^{\text {th }}$ ECCOMAS Thematic Conference on Computational Methods in Structural Dynamics and Earthquake Engineering M. Papadrakakis, M. Fragiadakis (eds.) Streamed from Athens, Greece, 28 - 30 June 2021

\title{
THE TARANTOLA ETRUSCAN PEDIMENT: NDT AND 3D MODEL CONTENT
}

\author{
A. L. Ciuffreda ${ }^{1}$, M. Coli ${ }^{1}$, T. Donigaglia ${ }^{1}$, P. I. Mariotti ${ }^{2}$, T. Salvatici ${ }^{1}$ and G. Simoni ${ }^{2}$ \\ ${ }^{1}$ Department of Earth Sciences, University of Florence \\ Via G. La Pira 4, 50121 Firenze, Italy \\ annalivia.ciuffreda@unifi.it; coli@unifi.it; tessa.donigaglia@unifi.it; teresa.salvatici@unifi.it \\ ${ }^{2}$ Opificio delle Pietre Dure \\ Via degli Alfani 78, 50122 Firenze, Italy \\ mariotti.p@gmail.com; gabriela.simoni01@gmail.com
}

\begin{abstract}
The Tarantola Etruscan pediment comes from a single-chamber tomb located in the Tarquinia area, dating back to 520-530 B.C.; it was found in 1904, during some agricultural works, close to Villa la Tarantola, from where the name. It consists of a trapezoidal tympanum $3.5 \mathrm{~m}$ long and $1 \mathrm{~m}$ high with a painting banquet with four diners (men) recumbent on a mattress placed at ground level. Fabrizio Lucarini detached it on behalf of the Royal Archaeological Museum of Florence, now National Archaeological Museum, where it is still conserved. The Tarquinia tombs were carved into the local Quaternary calcarenite named "Macco". The pictorial decoration was removed as solid-wall that was reinforced at the back with a layer of concrete. In the last years, the Tarantola pediment had been restored by the Opificio delle Pietre Dure (OPD). In the frame of a cooperation agreement between OPD and the Department of Earth Science (DST), it has been the subject of NDT analysis and survey for the reconstruction of a 3D model content. According to the MIBACT guideline (2011), the NDT surveys consisted into georadar, sonic and thermographic investigations. The location of the NDT data in their real space in the 3D model allowed their correct interpretation for a multidisciplinary evaluation about the structures of the pediment. The NDT survey also allowed identifying and locating minor and micro fissures and gypsum integrations below previous painting restorations. In conclusion, the $3 D$ modelling and NDT brought positive improvements for the structural and conservation knowledge of the Tarantola Etruscan pediment allowing better well-addressed restoration works.
\end{abstract}

Keywords: HBIM, 3D model, NDT investigations, Etruscan tomb, Cultural Heritage. 


\section{INTRODUCTION}

This paper investigates the potential of BIM (Building Information Modelling) methodology applied to cultural heritage. The methodology, used in architecture and engineering, allows to create a three-dimensional model of a project, inserting also the properties and information of any single object. This makes BIM a good way to manage cultural heritage projects, from historic buildings to artworks, in all phase of the restoration work.

The management of a cultural heritage object through an "informative model" presents difficulties related for example, to the modeling of non-standard forms and this is truer in the case of unique and particularly complex objects such as artworks.

The Tarantola pediment is an example of a mural painting detached as a solid-wall from its architectural context and therefore today it can be classified as a mobile artwork exhibited in a museum. Therefore, the pediment represents a case study halfway between wall paintings and artworks, and constitutes an opportunity for experimenting the application of the BIM methodology to objects such as artworks that are particular both for their uniqueness and for the complexity of the shapes.

This paper provides how this tool can be suitable for reconstructing the complex shapes of the cultural asset and at the same time constituting a repository of all the data for a correct $3 \mathrm{D}$ placing of all the information supporting the conservation and restoration activities.

A modeling based on a photogrammetric survey and the results of extensive NDT surveying campaigns formed the starting point for the case study represented by the Etruscan pediment of the Tarantola at the National Archaeological Museum of Florence (Italy).

The research has allowed a better address for the restoration of this mural painting that took place in 2019-2020 by the Opificio delle Pietre Dure.

To achieve this objective, the investigations followed the 2011 MIBACT Guidelines (point 4.1.6) [1] and were conducted by DST (Department of Earth Science), in full collaboration with the Museum and the Opificio delle Pietre Dure. The investigations carried out concerned the type and characteristics of the substrate for the Tarantola mural painting. The history of the pediment and its current assembly was studied and a series of non-destructive tests (NDT): GPR, sonic and ultrasonic and thermography.

\section{BIM APPLIED TO HISTORIC BUILDINGS AND ARTWORKS}

The preservation of the Italian historical and artistic heritage requires an in-depth diagnostic knowledge that is preparatory for every type of intervention and that expresses into nondestructive or slightly destructive investigations campaigns.

The MIBACT 2011 Guidelines [1], dedicated to historical-monumental buildings, draw attention to the historical and constructive knowledge of the asset.

This knowledge can be achieved by means of surveys and investigations that allow the acquisition of often hidden information (under plaster, behind false ceilings, etc.).

In this sense, the Guidelines consents for indirect non-destructive investigation techniques (thermography, georadar, sonic tomography, etc.) or weakly destructive direct inspections (endoscopies, peeling of plaster, essays, small burglaries, etc.).

The management of the knowledge deriving from the diagnostic campaign is always quite complex: there is a lack of coordination between the different disciplines, the multimedia supports are different with the risk of losing information and making difficult for future users to consult them.

In this section will be exposed a brief state of the art of BIM applied to cultural heritage. 


\subsection{State of art and normative references}

The use of digital models in restoration is a topic already investigated by several researchers in order to create a model as a single "container" (2D or 3D) to store geometric information and information relating to the intervention and maintenance phases on the artefact.

In this sense, we can cite examples of 2D Gis models such as Sicar (Information System developed by Liberologico and by the Superintendence of Fine Arts and Landscape for the provinces of Pisa and Livorno, in a working group that involved the National Research Council (CNR), Ministry for Cultural Heritage and Activities (MIBACT) and Small and Medium Enterprises), created to manage documents and analyzes collected during the restoration, or the applications of 3D-GIS by Barattin et al. [2].

In recent years, international studies have multiplied for the application of the BIM process to the historical architecture, the aim being a tool for classification, management and analysis of information. This process is called HBIM.

The first use of BIM applied to existing buildings is represented by the researches of Arayici [3] and Murphy et al. [4,5] who develop Historic Building Information Modeling (HBIM) by experimenting with libraries of parametric objects built from historical data with intelligent data integration and a system to map the parametric object on a point cloud.

Despite the difficulties encountered by these early authors, especially in the modeling phase, contributions on HBIM have multiplied to solve problems by simplifying the workflow of the restoration project and opening new ways for experimentation.

Among the topics covered are the modeling of objects starting from a point cloud [6,7], the enrichment of the model through the insertion of information or the reconstruction of the evolutionary phases of the building with the contributions of Apollonio et al., [8] and Brumana, et al., [9], the integration between BIM and GIS in the research of Dore and Murphy [10].

The methods of consulting the database through web platforms and augmented reality were also studied [11] and the construction of databases for building maintenance [12].

As part of the research activity carried out by the DST, various types of diagnostic investigations are performed on historical buildings and artworks: georadar investigations, sonic and ultrasonic investigations, video inspections, laboratory investigations on stones and mortars, micro-perforations, thermographic investigations, etc.

In order to organize the data collected during the research, 3D models of the cases studies are realized to highlight the geometric characteristics, as well as the location of the surveys in their real 3D location and the results in a unified framework.

This workflow was applied to case studies such as the Resurrection Christ by Piero della Francesca in Sansepolcro [13], the Garden of the Camelie and the Bona Hall in Palazzo Pitti [14].

Finally, a brief mention of the BIM legislation in Europe which has as its reference the "Directive on public procurement of the European Union" 2014/24 of 26 February 2014 [15] that invites EU Member States to encourage the use of BIM for projects, while Italy has adopted UNI 11337 [16] (divided into 10 parts), opening the discussion on the use of the BIM methodology to cultural heritage.

\section{THE ETRUSCAN PEDIMENT OF THE TARANTOLA}

The Tarantola pediment is a mural painting taken away as a solid-wall from a tomb in the necropolis of Tarquinia. The necropolis was excavated in the local soft calcarenite, called "Macco", which represents the support of the mural paintings that decorate the walls.

Since October 2018 the Pediment of the Tarantola is being restored at the Opificio delle Pietre Dure, as subject of a thesis by SAFS/PFP1 [17]. 


\subsection{Finding and conservative history}

The work, known in scientific literature as "Frontone della Tarantola" (Figure 1), was part of the mural decoration of an Etruscan tomb with a single chamber, it was originally located in the Tarquinia area within a property called the Tarantola fund, belonging to the Etruscan necropolis of Monterozzi. Dated around 520-530 B.C., it was found in 1904, during some agricultural works. The pictorial decoration located in the tympanum of the back wall inside the tomb was detached by Fabrizio Lucarini (a well-known restorer), on behalf of the Royal Archaeological Museum of Florence who bought the work from the owner of the land [18].

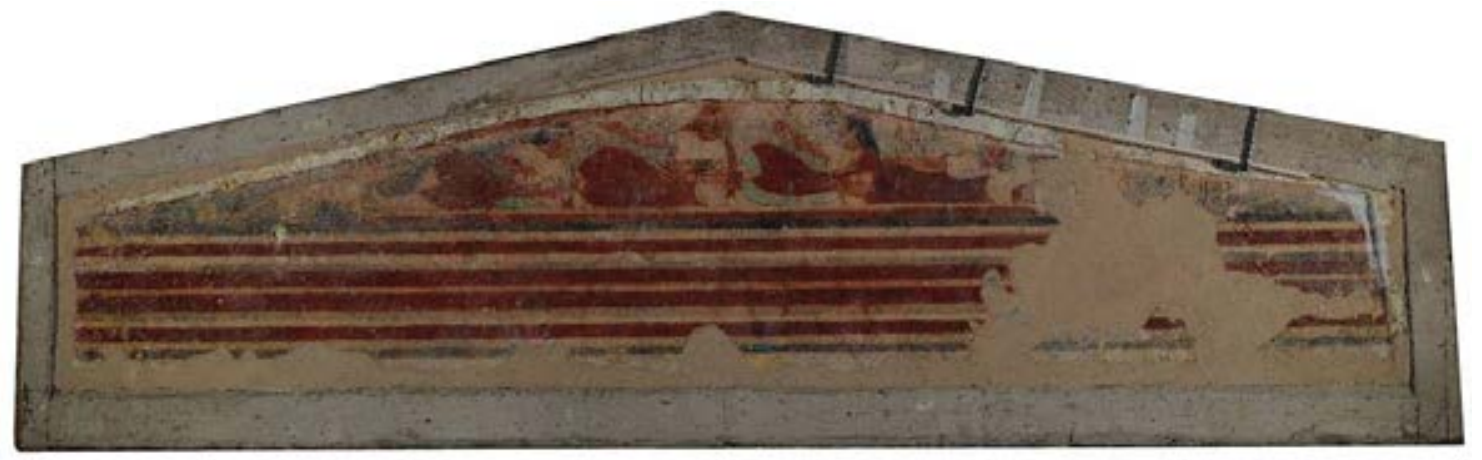

Figure 1: The pediment before the restoration.

The painting represents a banquet with four diners [19] (all men) recumbent on a mattress placed at ground level and a fair probably a lion, a panther or a particular species of dog. Below there are a continuous frieze of 13 bands in alternating colors, red, white, black and gray.

There are many reasons of interest: from the historical/artistic point of view, as a testimony of high value of Etruscan painting of the Archaic period (end of the 6th century B.C.) [20]; from the point of view of the history of the restoration, it represents a rare testimony of solidwall detachment framed in wood for strength and transport [21] and, very important, the wooden elements used to detach it still contribute to the conservation of the property, as the diagnostic investigations have confirmed. For the detachment of the painting from the buried tomb at a depth of 4.5 meters, a solid transport was carried out which involved the removal of both the pictorial decoration and the support: in fact, together with the pictorial surface, about $15-18 \mathrm{~cm}$ of stone were removed. In order to strength the removed Macco slab, Lucarini applied on the back first a layer of mortar (Malta Lucarini, made with Macco sand) and then a thin layer of concrete. Lucarini enclosed the fragment within a cusped wooden frame. For this reason, it can be assimilated to a pediment.

Since then, with the name of "pediment" (Frontone), due to its triangular shape, it has become part of the exhibition of the National Archaeological Museum of Florence [22]. After the flood of 1966, when it had suffered no particular damage [23], it was first transferred to the warehouses and then to the premises of the archaeological restoration laboratories and exhibited only during exhibitions, often abroad.

\section{THE INVESTIGATIONS CAMPAING FOR THE DEFINITION OF THE COGNITIVE FRAMEWORK}

The following section describes the research and analysis carried out to understand the materials and the state of conservation of the pediment. In the next paragraphs will analyze the types of NDT investigations carried out and will be showed the results obtained. 
The information deriving from the cognitive framework out-lined has been included in the BIM model as described in section 5.

\subsection{GPR survey}

The Ground Penetrating Radar (GPR) is a Non-Destructive investigation technique that was developed for investigating subsoil objects [24]; subsequently it was used for defining lithological contacts [25, 26], faults [27] and fractures in rock-mass [28, 29] and for defining soil units $[30,31]$ and the water table level too $[32,33,34]$.

GPR has been also applied in investigating the competence of concrete in bridges and tunnels and for the bonder durability. Recently GPR has been used for investigate masonry structure and assemblage [35, 36, 37].

The GPR principle uses the two-way travel time between a high-frequency electromagnetic input in the radar range $100 \mathrm{MHz}-100 \mathrm{GHz}$ and its return (Figure 2). The radar input travels in the material at a velocity mainly related to the magnetic conductivity and permeability of the medium [38, 39].
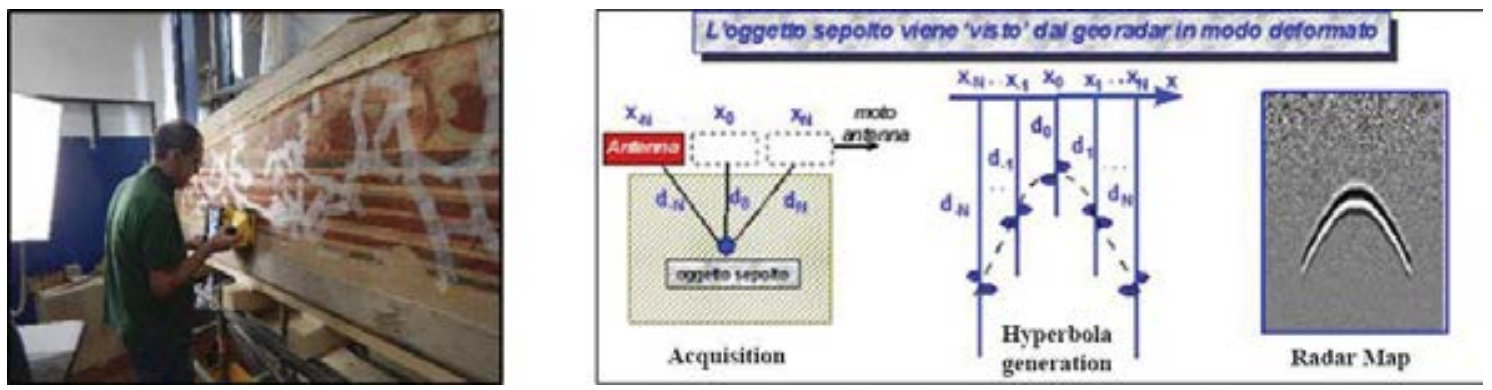

Figure 2: GPR operating on Tarantola pediment and principle: an antenna inputs a radar signal in the medium, the boundary between materials with different electromagnetic properties backscatters the signal to the receiver determining the two-way travel time.

The boundary between materials with different electromagnetic properties partially backscatter the signal to the antenna. The entity of penetration of the signal into the material is a function of the material properties and the signal frequency: lower is the frequency and higher is the penetration, but less are the details of the investigation because they are function of the wavelength.

The knowledge of the wave velocity in the medium or that of a distance of a sure signal are compulsory for fixing the scale of the investigation and therefore for correctly placed in the surveyed body the material interfaces, voids included.

In investigating a manufact, a good practice is measuring the thickness of the wall plus placing a still/iron plate as reference to the opposite side of investigation for having a sure end-signal of the masonry, in order to fix the scale of resulting radargram.

The Georadar campaign was carried out on the Tarantola pediment in collaboration with IDS Georadar S.R.L. (Hexagon Group), under the supervision of Dr. David Morandi, using the IDS C-Thrue system, with a $2 \mathrm{GHz}$ antenna (Figure 2). The acquisition campaign consisted into 4 horizontal scan-lines, spaced of $7-10 \mathrm{~cm}$, all along the entire length of the painted surface. Tomography analysis was made for having information relating to the material setting inside the pediment.

In order to avoid damaging the painting with the wheels of the instrument, the surface was temporarily consolidated in the most delicate areas. The GPR surveys, both the single horizontal surveys and the tomographic survey, were implemented in the 3D model (Figures 3 and 4). 


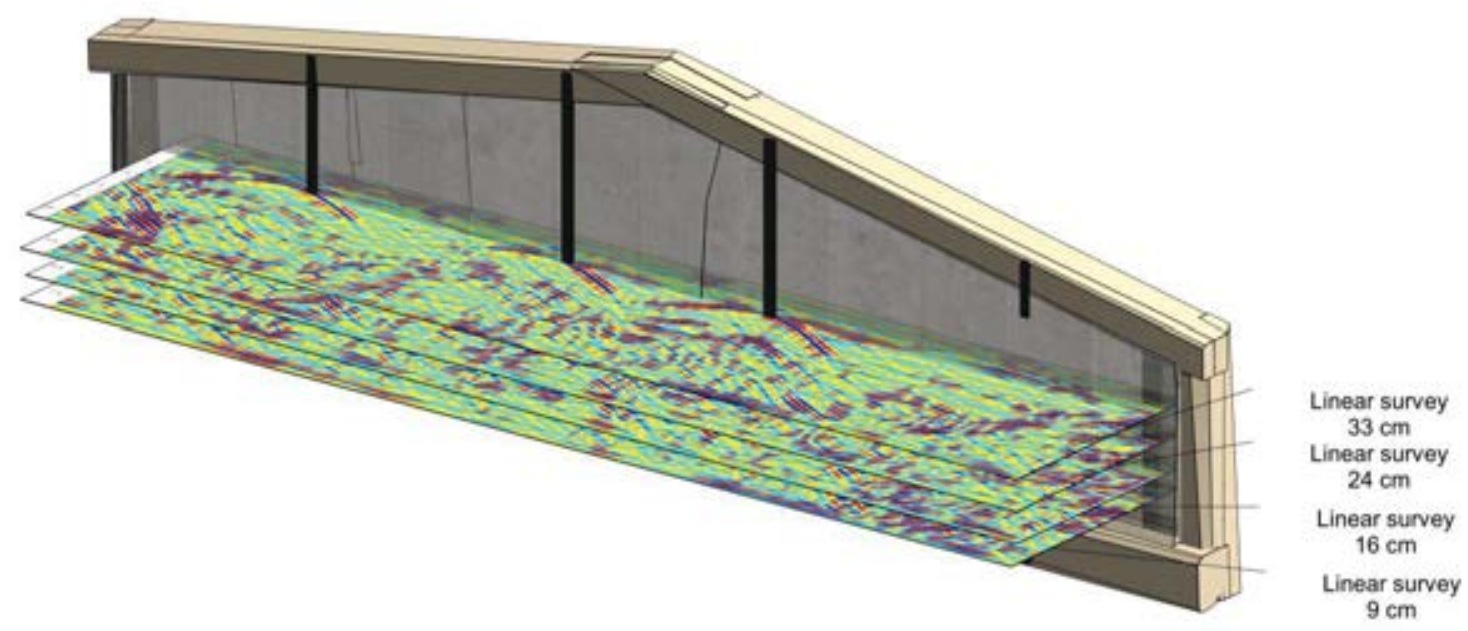

Figure 3: 3D mounting of GPR linear survey on the 3D model

The tomography results outline the Macco be affected by several discontinuities. On the right side of the pediment of concave shape up to a depth of approximately $5 \mathrm{~cm}$ is clearly visible, that is referred to a previous integration made by gypsum.

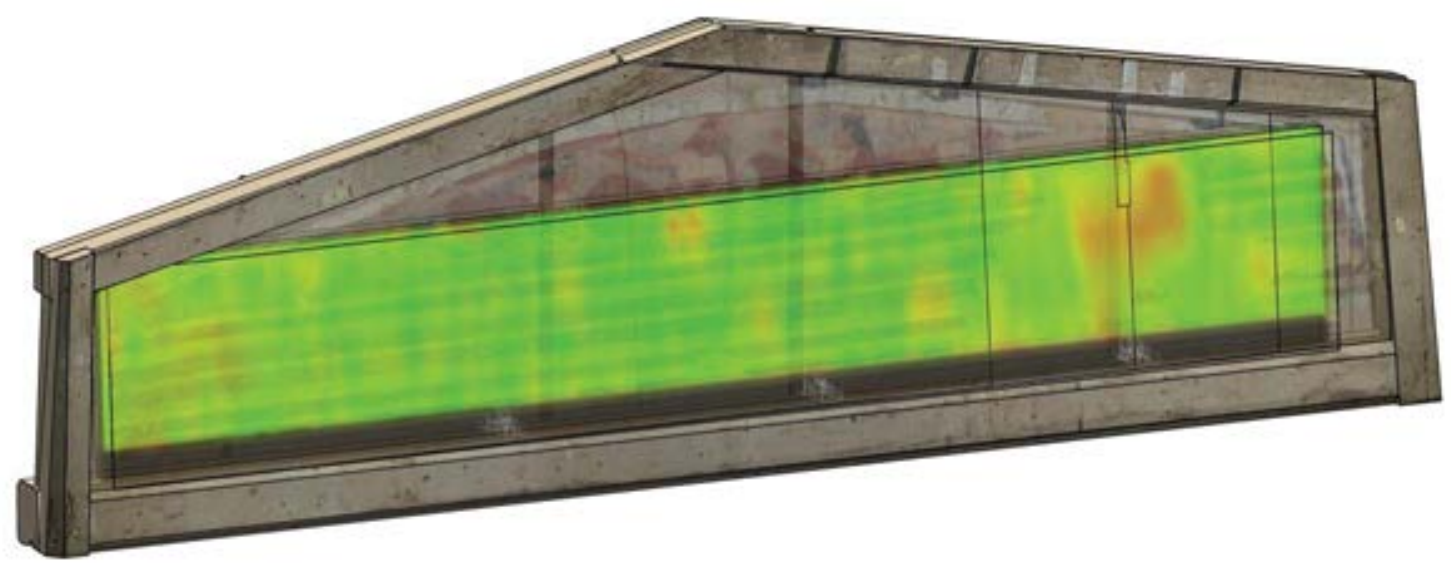

Figure 4: Georadar tomography in a section at $0.5 \mathrm{~cm}$ from the front surface, mounted on the 3D model.

Georadar analysis does not recognize the interface between Macco and Lucarini mortar because the composition of the mortar is very similar to that of the Macco, but well defines the interface with the concrete at the back.

\subsection{Sonic test}

The sonic test is based on the generation of elastic waves in the frequency range of sound $(20 \mathrm{~Hz}-20 \mathrm{kHz})$, by means of mechanical impulses generate by a hammer and recorded by a receiver.

The data acquisition system used was a Novasonic U5200 CSD module of IMG. The processing signal consisted of measuring waves travel times, a specific software allows the visualization of the transmitted and received signals on time domain [40]. The first arrival of the wave is obtained using an automatic algorithm that may be checked and corrected by the operator through visual access and manual operation.

Sonic pulse velocity tests were carried out on the Tarantola pediment following two configurations: direct and indirect [41] (Figure 5). 
In the first hammer and accelerometer are placed on opposite faces and the longitudinal waves are measured, in the second hammer and accelerometer are placed on the same face this method is more used to access to surface waves.

The pulse velocity represents the qualitative characteristics of the investigated object, influenced by composition, the contact between different materials, as well as by the presence of inhomogeneities, voids, cracks presence and deteriorated areas [42, 43, 44].

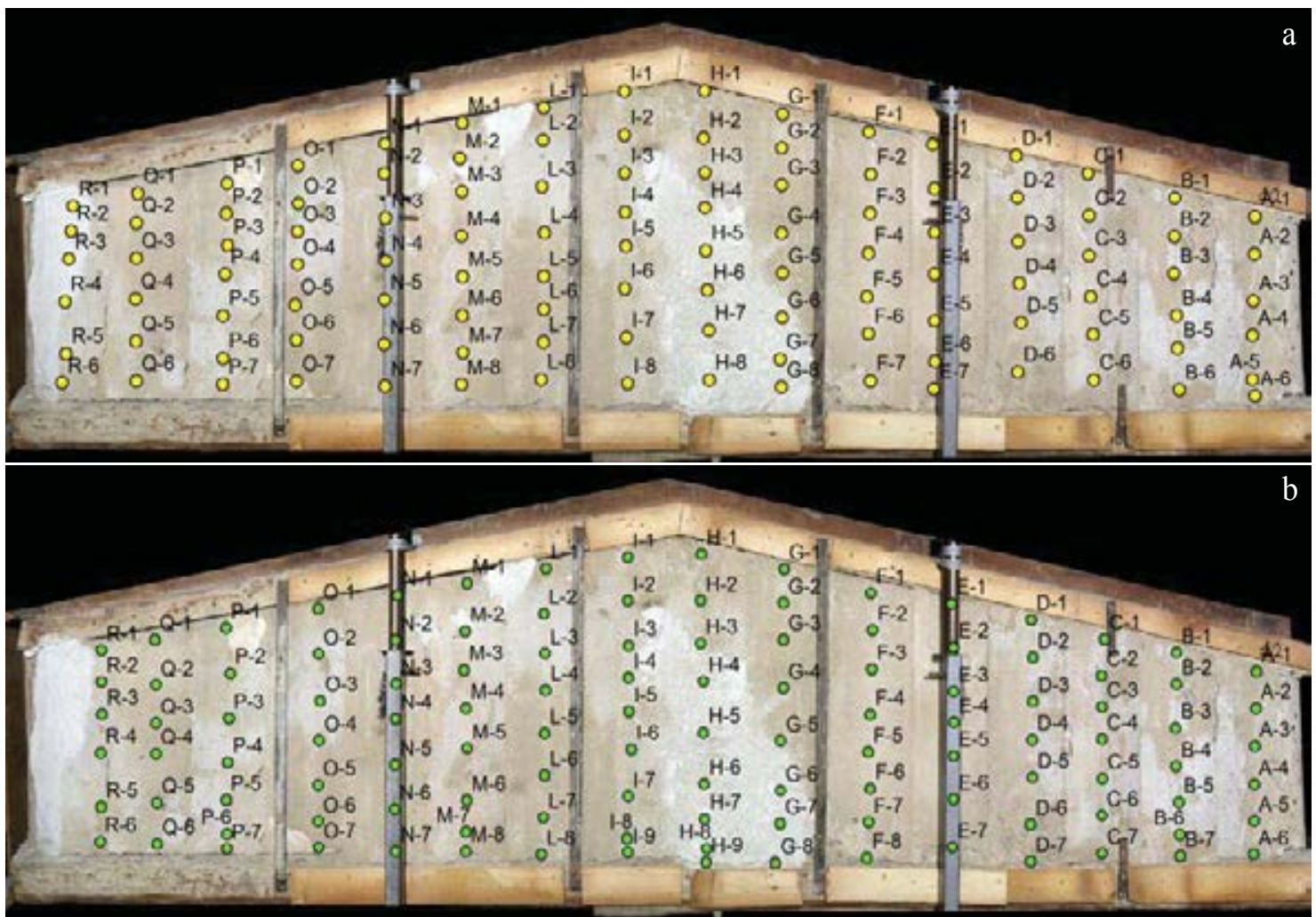

Figure 5: Sonic velocity test configurations, a) direct and b) indirect.

The direct acquisition was carried out considering 111 impact positions located on the back of Tarantola pediment along vertical alignments, while the receive was located in the front (Figure 5a). For each point, 3 trave times were recorded, and considering the thickness of Tarantola pediment as distance between the hammer and the receiver, the sound velocity was computed.

The indirect acquisition was carried out considering 16 impactions on the highest points of the vertical alignments and 100 receptions. For each point, 3 travel times were recorded, and considering the progressive distance between the hammer and the accelerometer, the sound velocity was computed (Figure $5 b$ ).

The punctual measurements were elaborated using ESRI ${ }^{\circledR}$ ArcGIS software, in particular the Natural Neighbor interpolation too [45], to compute a sonic velocity distribution map, the results, both direct and indirect, were reported on the 3D model (Figures 6 and 7) of the Tarantola pediment.

The average velocity of the two configurations is the same of about $600 \mathrm{~m} / \mathrm{s}$, this can be explained with the fact that the Tarantola pediment its constituted by a calcarenite (Macco) with an high porosity (20-30\%,) in addition some restoration supports as mortars and concrete in the back side and gypsum in front right side are present. 


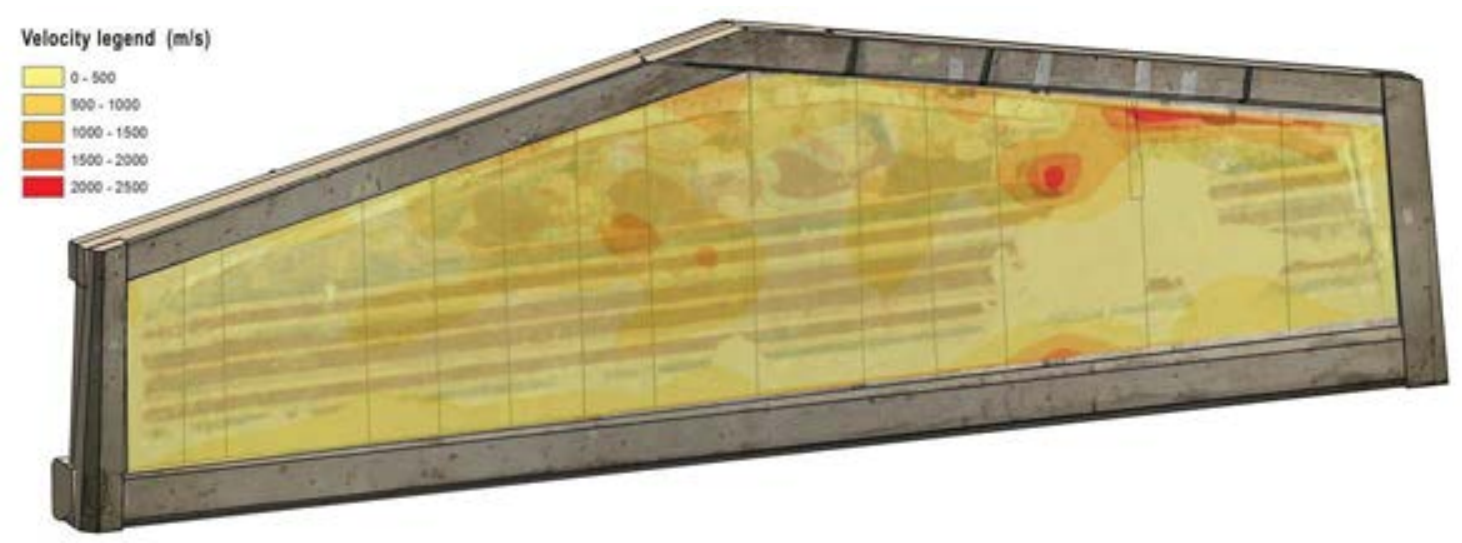

Figure 6: Sonic velocity from indirect acquisition mounted on the 3D model.

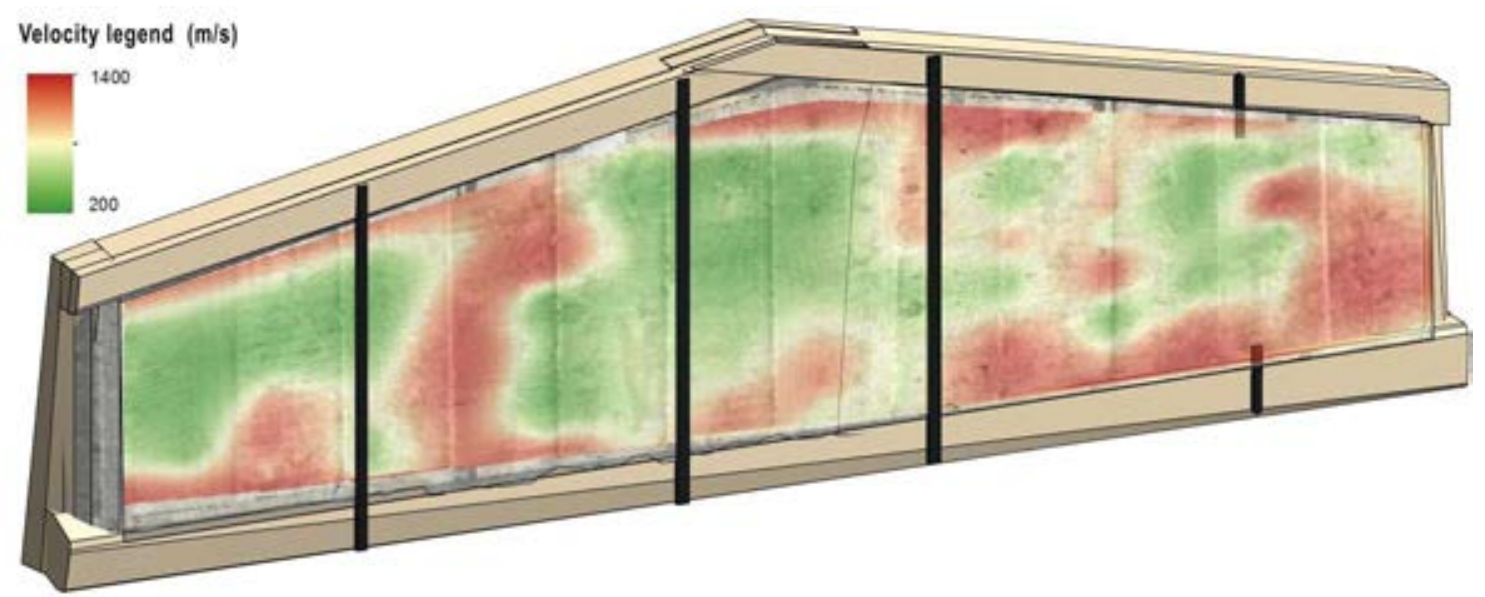

Figure 7: Sonic velocity from direct acquisition mounted on the 3D model.

All these materials lead to a general slowing down of the sound waves, indeed the indirect test shows an average velocity distribution on whole surface, this is the result of superficial velocity on the backside concrete and mortar layers, which is well distributed over the entire pediment.

Of particular interest are the result of direct test, on the back left side a higher speed area is present, this corresponds in the front of an area with the gypsum integration. The gypsum, in this case, is more homogeneous and compact and here the Macco is thinner and two different porous materials such as mortar and gypsum are in contact.

\subsection{Thermography campaign}

The use of thermography on the cultural heritage on masonry buildings allows, with specific conditions, the view of the internal layers hidden by the plaster; in particular, its use is still helpful to detect the structural part in the slabs and to check the texture of vaults and masonry walls.

Thermography on mural or panel paintings has some examples of use to detect various types of defects in the painting layer [46] or sublayer composition evaluation with the help of adapted image and signal processing algorithms to detect small discontinuities inside structures or extract material characteristic information [47].

Thermography is a no-contact test and can cover large areas. Thermography sums on the external surface the response from the while masonry, therefore it is difficult to detect the in- 
ternal anomalies in the artifact and results can be influenced by conditions and by nonhomogeneous heating.

In the case of the pediment, the experimental campaign has been made using a FLIR T460 thermal camera and was carried out in both passive and active conditions, heating the room evenly. The results of the thermographic campaign were subsequently inserted on the 3D model (Figure 8).

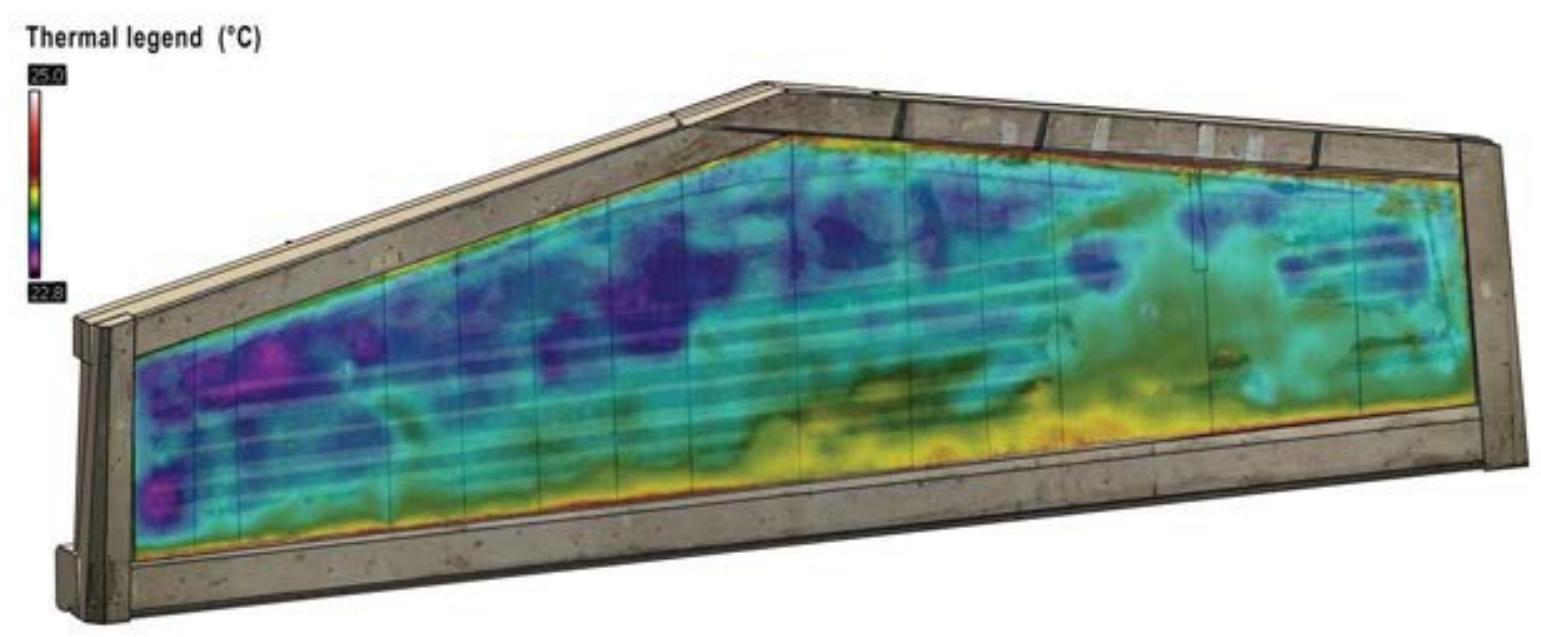

Figure 8: Visualization of the thermographic map inside the model.

In both cases, differences in temperature were detected due to the presence of different materials such as plaster repairs on the front, while no interesting anomalies were found on the back.

\section{THE DEFINITION OF THE INFORMATIVE MODEL}

In order to organize the data collected during the campaigns, a 3D model of the pediment was realized to highlight the structure, as well as the location of the surveys and their results in a unified framework.

In section 5.1 will describe the phase of the metric survey of the pediment by means of photogrammetry.

In sections 5.2 and 5.3 will describe the operational phase consisting of modeling the pediment and creating customized families for entering the data of the surveys carried out. It will also be presented how to enter data and query the database using specific methods.

\subsection{The photogrammetric survey}

The starting data for the geometry reconstruction of the pediment come from a photogrammetric survey. It was decided to use photogrammetry due to the speed of data collection and obtaining the results.

Photogrammetry is a technology that allows, starting from the acquisition of highdefinition images, the reconstruction of a textured 3D model.

It is already used for architectural, cartographic, topographical survey, and now it is also applied to artistic artefacts. It allows arriving at a detailed knowledge of the surfaces of the artwork in order to obtain information for conservation and valorization.

Using a $24 \mathrm{Mpx}$ camera, 1000 photographic shots were taken, taking care to maintain an adequate overlap between different frames and keeping the machine settings unchanged. The 
images were aligned and processed using photogrammetric software in order to obtain a point cloud (Figure 9) and a textured model (Figure 10).

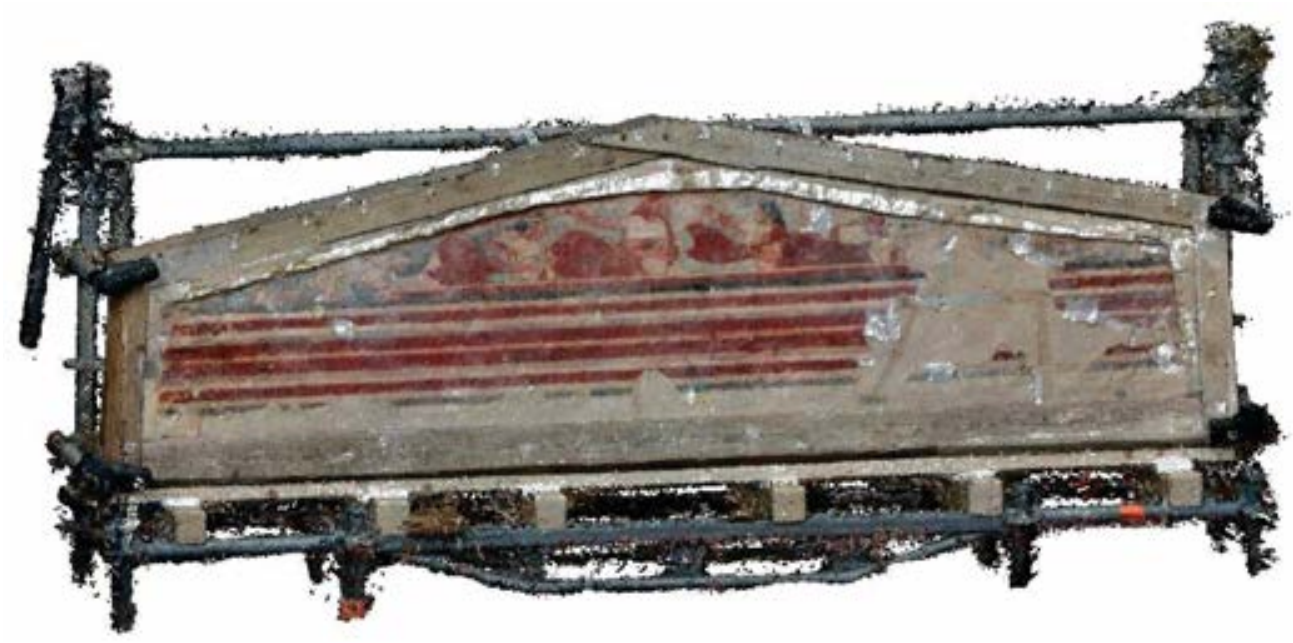

Figure 9: The point cloud deriving from the photogrammetric survey.

The point cloud of the pediment was imported into Autodesk Revit (®Autodesk academic license) for modeling in the BIM environment, while the orthophoto and textures for mapping the BIM model were obtained from the textured model.

The dense point cloud obtained consists of approximately 49.700 .000 points, which, during the processing of the mesh, give rise to approximately 9.900.000 triangular faces. The high density of the point cloud and the definition of the mesh made it possible to obtain an extremely detailed model.

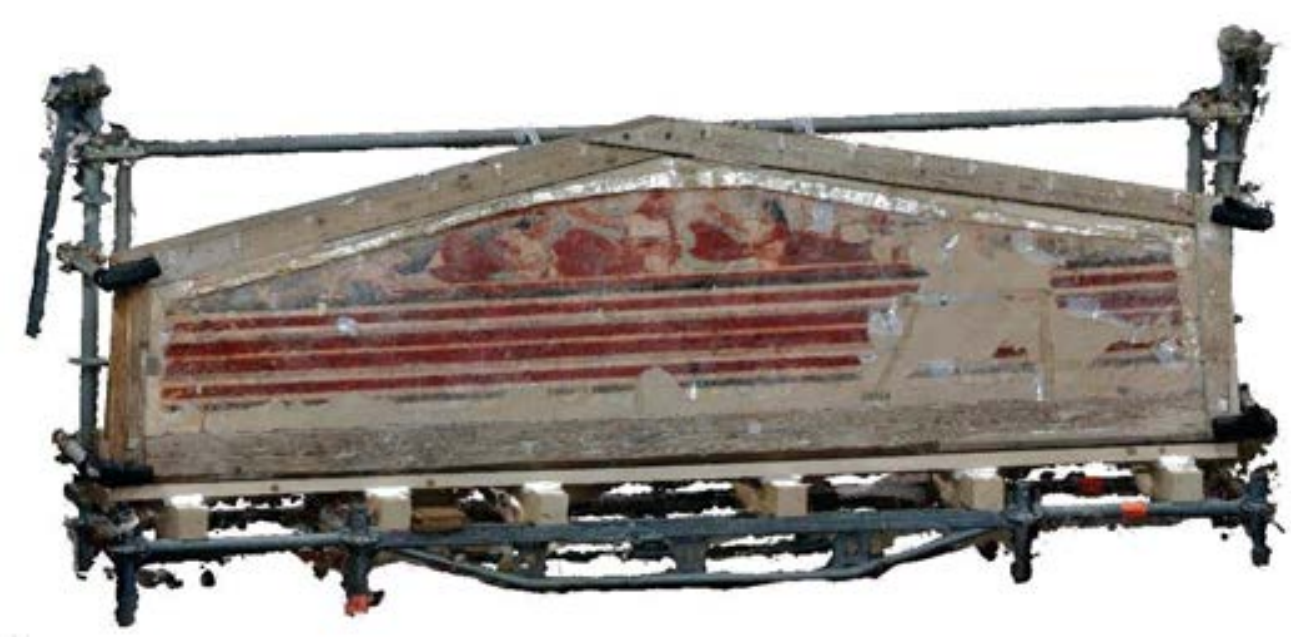

Figure 10: The textured model deriving from the photogrammetric survey.

\subsection{The modeling phase}

The difficulties of modeling cultural heritage objects in BIM environment are several, first of all the very irregular shapes. However, in this case, the choice to operate using BIM software is aimed at testing the potential for managing information related to cultural heritage.

It's useful to refer to the LOD achieved in the realization of model. The LOD provides the degree of reliability of the geometry detail level and information level. According to the BIM Forum Level of Development Specification [48] the model of the pediment can be framed in a 
LOD 300. If this level is accurate, geometric data can be measured directly on the model and any type of information (materials, decay, historical data, etc.) can be added via external references. Therefore, the three-dimensional model were made with attention to the modelling of the structure and archiving the results of the diagnostic campaign.

The pediment was modeled trying to be true to its shape and features using Autodesk Revit software. The greatest difficulty is due to the not perfectly planar conformation of the wooden frame and the pediment. Starting from a reference level, the Revit wall system families were used to model the layers that make up the artwork, in particular the Macco.

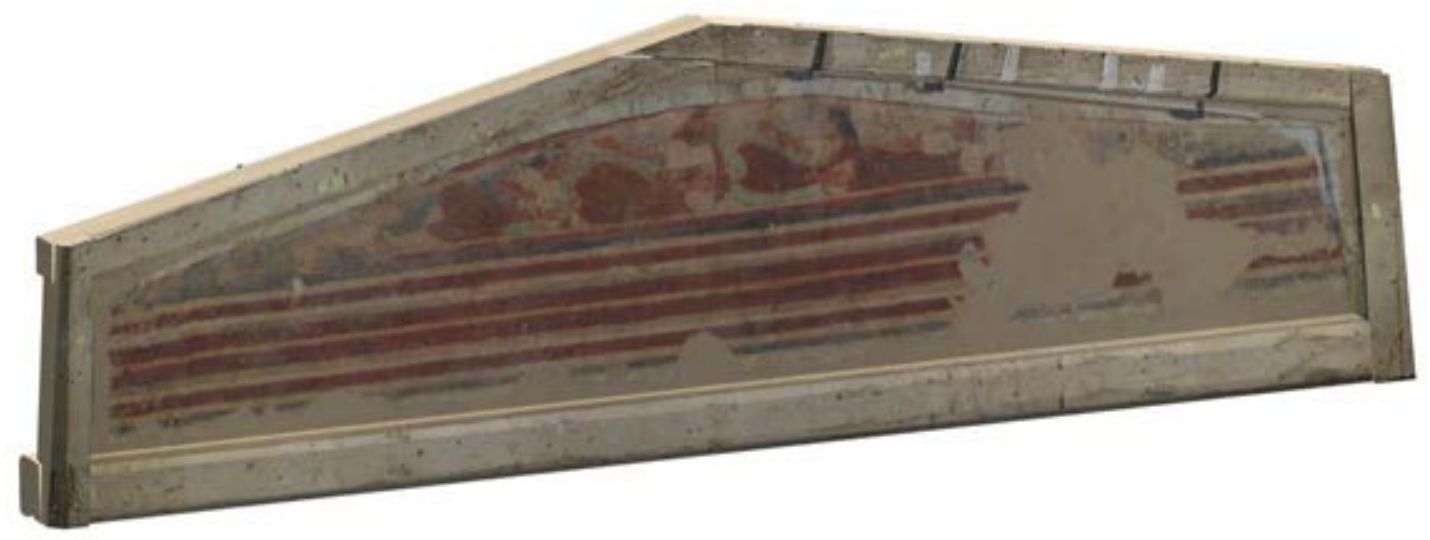

Figure 11: A general view of the BIM model.

Wall-objects were created with customized stratigraphy and materials that had suitable textures to guarantee the recognizability of the different structures (Figures 11 and 12). Instead, the wooden frame was modeled using parametric beam elements.

We have tried to use in place modeling as little as possible, which is often not recommended as it is a traditional methodology that goes beyond the rules of BIM, creating non-reusable objects that weigh down the file. Therefore, every object that could not be modeled with a system family, such as the beams of the frame, was inserted starting from a parameterized and customized family that can be further enriched with information.

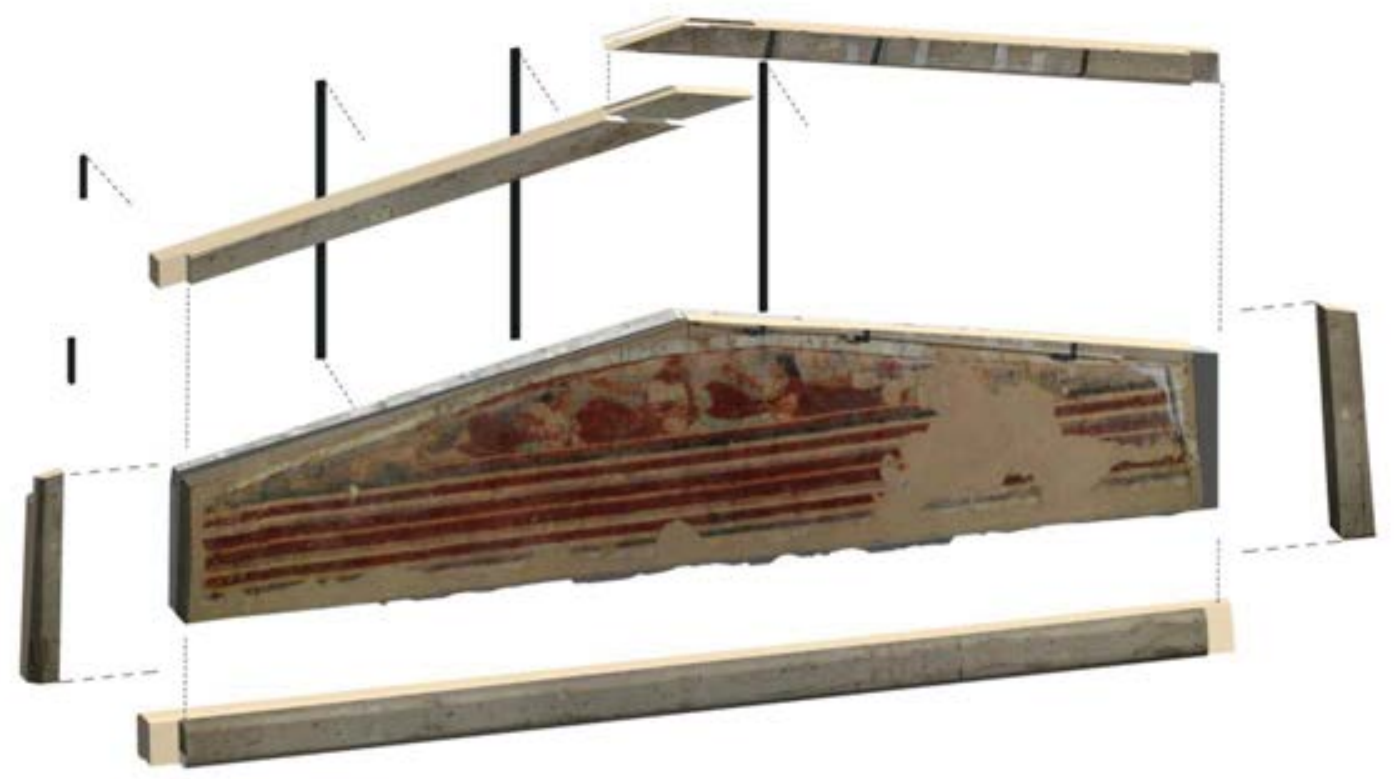

Figure 12: Exploded view of the BIM model. 
The inclusion of the surveys in the model was addressed through the creation of specific families to which the parameters described in section 5.3 are linked. The geometry of the objects that represent the surveys has been studied according to its characteristics (Figures 5-8).

For example, the georadar survey was modelled on a panel of variable dimensions. This mode allows a faster and more efficient visualization and understanding of the model.

All this led to create a family library that allowed a rapid modelling of the case study and can be reused in future works.

The BIM model was designed to facilitate the understanding of the wall structure of the painting, to store information found during the diagnostic campaign and during restoration, and to allow easy viewing and consultation.

\subsection{The implementation of the informative model}

This work phase illustrates how the data were entered into the model and how it was assigned to each object.

For each element modeled in $3 \mathrm{D}$, it is possible to connect data relating to the general characteristics of the element, to the dimensions, the results of the investigations, the materials and the monitoring data, etc. It is also possible to associate links to external files such as images, videos, documents.

Each object was created within an appropriate category, and preferably associated with instance parameters. All parameters are shared and subsequently converted into project parameters, linking them to the relevant category.

The families of the surveys have been associated with parameters that allow inserting information such as the date of execution, the description, the instrument used and the results. It was possible to create parameters to insert links to photos, documents and videos.

Parameters such as dimensions, wood essence, dating were associated to the beams of the frame, while the characteristics of the materials were associated with the layers constituting the support. Each object has been provided with an ID that identifies it and which can be viewed using the appropriate label. The creation of abacus allowed the classification of the objects by cate-gory and the interrogation of the model (Figure 13).

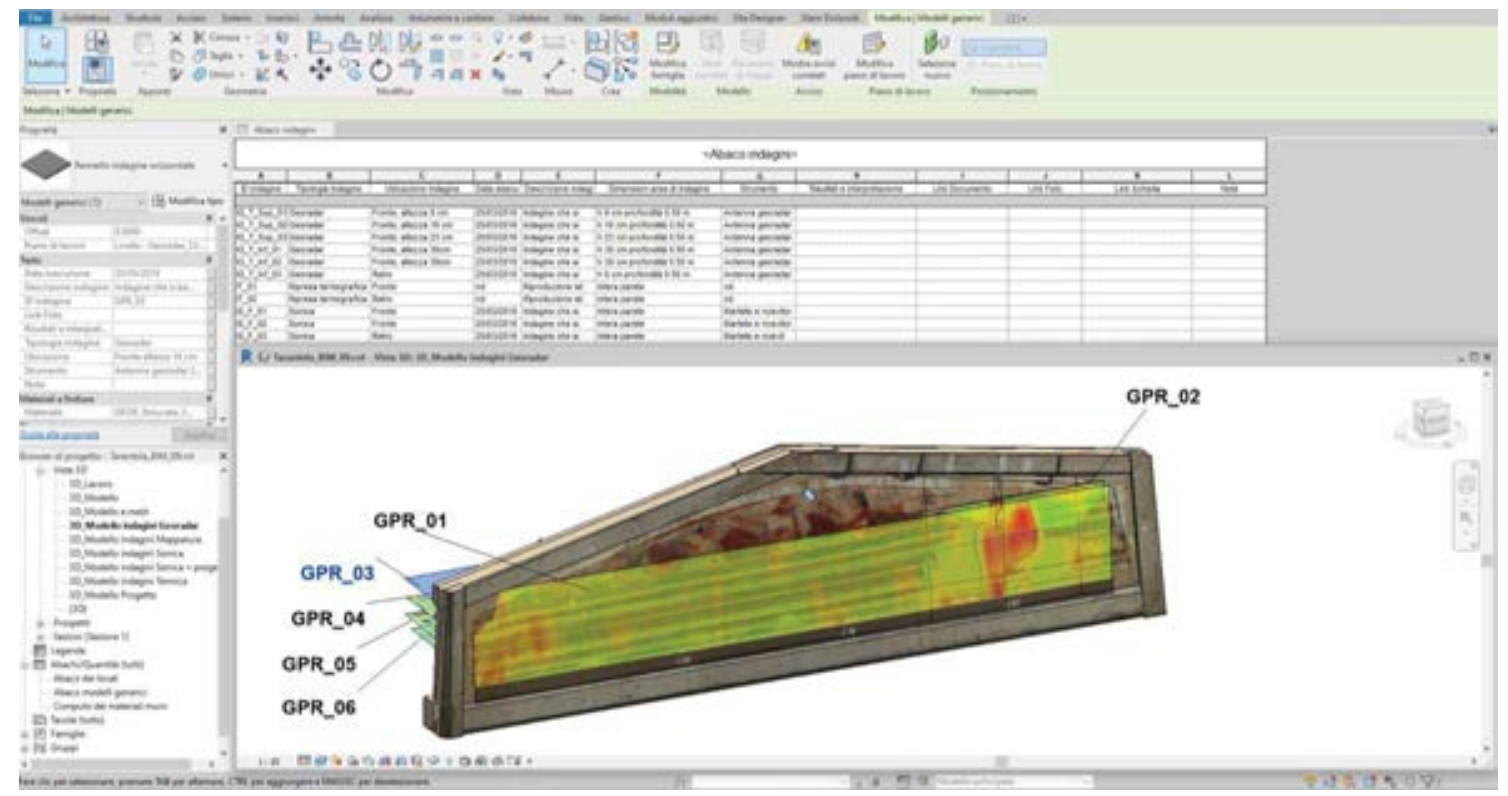

Figure 13: The identification of the surveys by label, the visualization of the parameters connected to the object, and an example of abacus that allow managing all the surveys. 
By selecting an element inside the abacus, Revit allows to view it within the model. Furthermore, the objects inside the schedules can be filtered and sorted according to the parameters created, making it easy to interrogate even very complex models.

Revit software also allows managing the visualization of the model through customized views and in the $3 \mathrm{D}$ environment through dynamic sections and exploded view that facilitate in the modeling phase and in the public presentation phase of the research results.

The creation of specific abacus allowed the interrogation the model. The model was subsequently organized through specific views aimed at displaying the different types of information to be highlighted.

The result obtained is a digital twin of the artwork, which makes it possible to analyze the results of the investigations in close relation with the areas investigated and to locate and measure any anomalies.

\section{CONCLUSIONS AND FUTURE DEVELOPMENT}

The workflow presented made it possible to test the possibilities of digitization and archiving using the BIM methodology applied to a very particular case study of cultural heritage.

The result is a model that describes with a good level of detail the current state of the pediment and its wall support, while the information was stored in a simple and easily accessible way.

Even in this particular case study, BIM is a valid tool for management and storage for the speed of modeling thanks to parameterization.

Among the problems encountered are the difficulty of modeling complex elements with non-standard forms, the lack of categories related to the restoration and diagnostic process, the absence of information classification procedures and the lack of a single system that allows consultation and implementation of the model without using BIM software.

This last aspect can be partially solved using an online viewer or an IFC viewer, which however remain limited and allow consulting the information but do not always allow the visualization of the textures and many others problem.

The next steps of the DST research aim to study a way to consult the model also on mobile devices and without having to choose a BIM Authoring software.

Future developments foresee a double aspect: on the one hand, the creation of centralized models with multidisciplinary information that can be used in the field of conservation and enhancement of the single building or artwork, on the other hand complex databases will be created for management of museums as containers of artworks or, more generally, for the cultural heritage of entire cities.

\section{REFERENCES}

[1] DPCM 9 febbraio 2011. Linee guida per la valutazione e riduzione del rischio sismico del patrimonio culturale, allineate con alle Nuove Norme Tecniche per le costruzioni 2008 (NTC 2008), Gazzetta Ufficiale n. 47 del 26-2-2011 - Suppl. Ordinario n. 54.

[2] L. Baratin, S. Bertozzi, E. Moretti, Tecnologia GIS per la manutenzione programmata dei beni culturali. La conservazione preventiva e programmata-PCC Conference 2014, Monza-Mantova, 2014.

[3] Y. Arayici, Towards building information modelling for existing structures. Structural Survey, 26, 210-222, 2008. DOI: 10.1108/02630800810887108. 
[4] M. Murphy, E. McGovern, S. Pavia, Historic Building Information Modelling - Adding intelligence to laser and image-based surveys of European classical architecture. ISPRS Journal of Photogrammetry and Remote Sensing 76, 89-102, 2013. DOI:10.1016/j.isprsjprs.2012.11.006.

[5] M. Murphy, E. McGovern, S. Pavia, Historic building information modelling (HBIM). Structural Survey, 27, 311-327. 2009. DOI:10.1108/02630800910985108.

[6] S. Garagnani, A.M. Manferdini, Parametric accuracy: building information modeling process applied to the cultural heritage preservation. ISPRS - In International Archives of the Photogrammetry, Remote Sensing and Spatial Information Sciences, XL-5/W1, 87-92, 2013. DOI:10.5194/isprsarchives-XL-5-W1-87-2013.

[7] L. Barazzetti, F. Banfi, R. Brumana, M. Previtali, Creation of parametric BIM object from point clouds using NURBS. The photogrammetric Record, 30 (152), 339-362, 2015. DOI: $10.1111 /$ phor.12122.

[8] F. I. Apollonio, M. Gaiani, Z. Sun, 3D modeling and data enrichment in digital reconstruction of architectural heritage. ISPRS-International Archives of the Photogrammetry, Remote Sensing and Spatial Information Sciences, XL-5/W2, 43-48, 2013. DOI:10.5194/isprsarchives-XL-5-W2-43-2013.

[9] R. Brumana, D. Oreni, A. Raimondi, A. Georgopoulos, A. Bregianni, From survey to HBIM for documentation, dissemination and management of built heritage. The case study of St. Maria in Scaria d'Intelvi. Proceedings of the DigitalHeritage 2013Federating the 19th Int'l VSMM, 10th Eurographics GCH, and 2nd UNESCO Memory of the World Conferences, Plus Special Sessions from CAA, Arqueologica 2.0 et Al. IEEE, 497-504, 2013. DOI:10.1109/DigitalHeritage.2013.6743789.

[10] C. Dore, M. Murphy, Integration of Historic Building Information Modeling (HBIM) and 3D GIS for recording and managing cultural heritage sites. 18th International Conference on Virtual Systems and Multimedia. IEEE, 69-376, 2012. DOI:10.1109/VSMM.2012.6365947.

[11] L. Barazzetti, F. Banfi, R. Brumana, D. Oreni, M. Previtali, F. Roncoroni, HBIM and augmented information: Towards a wider user community of image and range-based reconstructions. ISPRS-International Archives of the Photogrammetry, Remote Sensing and Spatial Information Sciences, XL-5/W7, 35-42, 2015. DOI:10.5194/isprsarchivesXL-5-W7-35-2015.

[12] F. Fassi, C. Achille, A. Mandelli, F. Rechichi, S. Parri, A new idea of BIM system for visualization, web sharing and using huge complex 3D models for facility management. ISPRS -International Archives of the Photogrammetry, Remote Sensing and Spatial Information Sciences, XL-5/W4, 359-366, 2015. DOI:10.5194/isprsarchives-XL-5-W4359-2015.

[13] M. Coli, A. L. Ciuffreda, M. Micheloni, An informative content 3d model for the hall holding the Resurrection of Christ by Piero della Francesca mural painting at Sansepolcro, Italy. ISPRS - International Archives of the Photogrammetry, Remote Sensing and Spatial Information Sciences, XLII-2/W11, 435-442, 2019. 10.5194/isprs-archivesXLII-2-W11-435-2019. 
[14] M. Coli, A. L. Ciuffreda, T. Donigaglia, Informative models for the cultural heritage buildings: applications and case histories. A. Conte, A. Guida, ReUso 2019. Matera. Patrimonio in divenire. Conoscere, valorizzare, abitare, Gangemi Editore, 2020.

[15] Directive 2014/24/EU 26 February 2014. Directive on public procurement and repealing Directive 2004/18/EC.

[16] UNI 11337. Edilizia e opere di ingegneria civile - Gestione digitale dei processi informativi delle costruzioni.

[17] Historical Archive of the National Archaeological Museum of Florence, III vers. II. Part, 1904-1907, envelope 64, fasc. 9bis, N. prot. 4960. of March 18, 1904. Direction of the archaeological museum and of the excavations of antiquity in Etruria, Florence, Posiz. F / 18, Prot. 546, n. of part. 28, Object: painted tomb in Corneto Tarquinia.

[18] M. Marzullo, The glass of farewell. Banquet and funerary space in Tarquinia, in The symbolic banquet. Parties, symposia and bacchanals between ancient rituals and modern anachronisms, Jouvenca, Milan, 2016, p. $81 \mathrm{ff}$.

[19] G. Simoni, The panted pediment of the Etruscan tomb of the Tarantola. Executive technique, conservation, project and restoration intervention. Thesis by SAFS / PFP1, 2020.

[20] A. Cecchini, The painted tombs of Tarquinia conservation story, technical execution restorations. Kermesquaderni, Nardini Editore, Florence, 2012.

[21] M. Marzullo, Grotte Cornetane, Material and critical apparatus for the study of painted tombs of Tarquinia, University of Milan, TARCHNA, Excavations and research in Tarquinia, supplement 6, Ledizioni, Milan 2016, Voll. I pp. 7, 353-354 (Pediment), 106108 (Tomb 5898 032), Voll. II pp. 658-661 (Tomb 5039-312), 745-746 (Tomb 5517333.

[22] L. A. Milani, The Royal Archaeological Museum of Florence, its history and illustrated guide, Deposit at Succ. B. Seeber, Florence, 1923, II vol., Pag. 245.

[23] A. Minto, Il Regio Museo Archeologico di Firenze, La Libreria dello Stato, Roma, A. x E. F., pp. 58.

[24] P.K. Fuliagar, D. Livleybrooks, Trial of Tunnel Radar for cavity and One Detection in the Sudbury Mining Camp, Ontario. Proceedings of the Fifth International Conference on Ground Radar, Waterloo centre for Groundwater research, Waterloo, Canada, 88394, 1994.

[25] U. Basson, Y. Enzel, R. Amit, Z. Ben-Avraham, Detecting and Mapping Recent Faults with a ground-Penetrating Radar in the Alluvial Fans of the Arava Valley. Proceedings of the Fifth International Conference on Ground Radar, Waterloo centre for Groundwater research, Waterloo, Canada, 777-88, 1994.

[26] S. Van Heteren, D.M. Fitzgerald, P.S. McKinlay, Application of Ground-Penetrating Radar in the Coastal Stratigraphic Studies. Proceedings of the Fifth International Conference on Ground Radar, Waterloo centre for Groundwater research, Waterloo, Canada, 869-81, 1994.

[27] S. Deng, Z. Zhengrong, H. Wang, The Application of Ground Penetrating Radar to Detection of Shallow Faults and Caves. Proceedings of the Fifth International Conference on Ground Radar, Waterloo centre for Groundwater research, Waterloo, Canada, 111533, 1994. 
[28] L. Bjelm, Geologic Interpretation of SIR Data from Peat Deposit in Northern Sweden. Unpublished manuscript, Department of Engineering Geology, Lund Institute Technology, Lund, Sweden, 1980.

[29] D. Moffat, R. Puskar, A Subsurface Electromagnetic Pulse Radar. Geophysics, 41, 506$18,1976$.

[30] M.E. Collins, Soil Taxonomy: A Useful Guide for the Application of Ground Penetrating Radar. Proceedings of the Fourth International Conference on Ground Radar, edited by P. Hanniend and S. Autio, Rovaniemi, Finland, 125-32, 1992.

[31] S.F. Shih, J.A. Doolittle, Using Radar to Investigate Organic Soil Thickness in the Florida Everglades. Soil Science Society of America Journal, 48, 651-6, 1984.

[32] J.A. Doolittle, L.E. Asmussen, Ten Years of Applications of Ground Penetrating Radar by the United States Department of Agriculture. Proceedings of the Fourth International Conference on Ground Radar, edited by P. Hanniend and S. Autio, Rovaniemi, Finland, 139-47, 1992.

[33] L. Beres, H. Haeni, Application of Ground-Penetrating Radar Methods in Hydrogeologic Studies. Groundwater, 29, 375-86, 1991.

[34] R.A. Overmeeren, High Speed Georadar Data Acquisition for Groundwater Exploration in the Netherlands. Proceedings of the Fifth International Conference on Ground Radar, Waterloo centre for Groundwater research, Waterloo, Canada, 1057-73, 1994.

[35] M. Pieraccini, M. Fratini, F. Parrini, G. Macaluso, C. Atzeni, High-Speed CW StepFrequency Coherent Radar for Dynamic Monitoring of Civil Engineering Structures. Electron Lett, 40 (14), 907-8, 2004.

[36] M. Coli, T. Donigaglia, P. Papeschi, F. Boscagli, GPR Investigation for Historical Masnory: Case Histories from Florence (Italy) Cultural Heritage Monumental Buildings. $3^{r d}$ Int. Conf. on Techniques, Measurements \& Materials in Art \& Archaeology, Jerusalem, Israel, 2018.

[37] M. Coli, P. Papeschi, F. Boscagli, L. Innocenti, B. Agostini, GPR Investigation on the Masnory of the Brunelleschi's Cupola, Florence (Italy). Giornale delle prove non distruttive, Monitoraggio, Diagnostica AIPnD, 1, 52-7, 2018.

[38] A.P. Annan, W.M. Waller, D.W. Strangway, J.R. Rossiter, J.D. Redman, R.D. Watts, The Electromagnetic Response of a Low_Loss, 2-Layer, Dielectic Earth for Horizontal Electric Dipole Extraction. Geophysics, 40, 285-98, 1975.

[39] GSSI - Geophysical Survey Systems, Inc, Operations Manual for Subsurface Interface Radar System -3. Manual \#MN83-728. Geophysical System, North Salem, New Hampshire, 1987.

[40] N.J. Carino, The Impact-echo method: An Overview. Building and Fire Research Laboratory. National Institute of Standards and Technology: Gaithersburg, 2001.

[41] ACI 228.2R 98, Nondestructive Test Methods for Evaluation of Concrete in Structures.

[42] L.F. Miranda, J. Rio, J.M. Guedes, A. Costa, Sonic impact method-a new technique for characterization of stone masonry walls. Constr Build Mater, 36, 27-35, 2012. 
[43] L. Miranda, L. Cantini, J. Guedes, A. Costa, Assessment of mechanical properties of full-scale masonry panels through sonic methods. Comparison with mechanical destructive tests. Struct Control Heal Monit., 23, 503-516, 2016.

[44] T. Salvatici, S. Calandra, I. Centauro, E. Pecchioni, E. Intrieri, C.A. Garzonio. Monitoring and evaluation of sandstone decay adopting non-destructive techniques: On-site application on building stones. Heritage, 3, 1287-1301, 2021.

[45] R. Sibson, A Brief Description of Natural Neighbor Interpolation, chapter 2 Interpolating Multivariate Data. New York: John Wiley \& Sons, 21-36, 1981.

[46] M. Rippa, V. Pagliarulo, A. Lanzillo, M. Grilli, G. Fatigati, P. Rossi, P. Cennamo, G. Trojsi, P. Ferraro, P. Mormile, Active Thermography for Non-invasive Inspection of an Artwork on Poplar Panel: Novel Approach Using Principal Component Thermography and Absolute Thermal Contrast, Journal of Nondestructive Evaluation, 2021. 40. 10.1007/s10921-021-00755-Z.

[47] G. Steenackers, J. Peeters, K. Janssens, Sublayer composition evaluation of Artwork using active thermography. Quantitative InfraRed Thermography, 2018, 10.21611/qirt.2018.049.

[48] Bim Forum, Level of Development (LOD), Specification Part I \& Commentary for Building Information Models and Data, April 2019. 